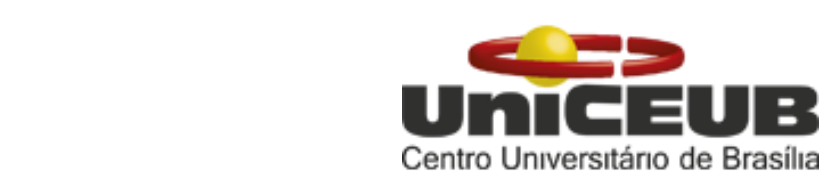

CENTRO UNIVERSITÁRIO DE BRASÍLIA - UniCEUB PROGRAMA DE INICIAÇÃO CIENTÍFICA

CLÉVESSON SOUZA SANTOS KIMBERLY GUIDA CARVALHO

ANALISE EPIDEMIOLÓGICA E DOS CUSTOS DIRETOS DA MICROCEFALIA RELACIONADA À INFECÇÃO PELO VÍRUS ZIKA NO BRASIL

BRASÍLIA

2018 


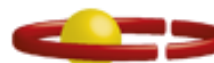 \\ UnICEUB \\ Centro Unıversıtárıo de Brasílıa \\ CLÉVESSON SOUZA SANTOS \\ KIMBERLY GUIDA CARVALHO}

\section{ANALISE EPIDEMIOLÓGICA E DOS CUSTOS DIRETOS DA MICROCEFALIA RELACIONADA À INFECÇÃO PELO VÍRUS ZIKA NO BRASIL}

Relatório final de pesquisa de Iniciação Científica apresentado à Assessoria de Pós-Graduação e Pesquisa pela Faculdade de Ciências da Educação e da Saúde - FACES.

Orientação: Julliane Messias Cordeiro Sampaio

\section{BRASÍLIA}




\title{
ANALISE EPIDEMIOLÓGICA E DOS CUSTOS DIRETOS DA MICROCEFALIA RELACIONADA À INFECÇÃO PELO VÍRUS ZIKA NO BRASIL
}

\author{
Kimberly Guida Carvalho - UniCEUB, PIC Institucional, aluno bolsista \\ kimberlyguidac@gmail.com
}

Clévesson Souza Santos - UniCEUB, PIC institucional, aluno voluntário clevesson.souza.santos@gmail.com

Julliane Messias Cordeiro Sampaio - UniCEUB, professora orientadora Julliane.sampaio@ceub.edu.br

Henry Maia Peixoto- UnB, PIC Institucional, colaborador. henrymaiap9@gmail.com

Luciana Guerra Gallo - UnB, PIC Institucional, colaborador. lucianaggallo@gmail.com

A microcefalia é uma doença que gera uma série de alterações no sistema nervoso da criança afetada, sendo de origem multifatorial, variando de anomalias congênitas, substâncias teratogênicas, má nutrição grave durante a formação do feto, a infecção na gestante ocasionada pelo vírus Zika, sendo que esta última foi descoberta recentemente. A microcefalia ocasionada pelo ZIKA vírus, foi detectada após o surto em Pernambuco no Brasil, no entanto ainda não se tem conhecimento ao certo do mecanismo que gera a morbidade no feto, mas sabe-se que a transmissão é vertical e as alterações morfofisiológicas variam de acordo com a idade gestacional em que ocorre o acometimento pelo vírus. A presente pesquisa foi realizada no intuito de conhecer os dados sociodemográficos dos acometidos no ano de 2016 e mesurar os custos diretos relacionados à microcefalia ocasionada pelo vírus Zika, para isso foram realizados estudos epidemiológicos descritivo de casos de microcefalia no Brasil e avaliação econômica parcial, considerando os custos da hospitalização obtidos a partir da análise do Sistema de Informação Hospitalar Descentralizados (SIH/SUS). Os valores de custos, identificados em anos diferentes dos anos avaliados, foram ajustados para o ano de 2016, com base na taxa oficial de inflação estimada pelo Índice Nacional de Preços ao Consumidor Amplo (IPCA) acumulado. Foi identificado o universo de 991 casos confirmados e prováveis de microcefalia pelo Vírus Zika, sendo que destes apenas 2,93\% ( $\mathrm{N}=29)$ foram detectados durante a gestação, e $97,07 \%(\mathrm{~N}=962)$ no pós-parto, além disso, 50,96\% ( $N=505)$ das gestantes apresentaram sintomas da infecção pelo vírus Zika, indicando assim um atraso na detecção destes, em muitos casos derivado da incerteza da correlação da infecção pelo vírus Zika com a microcefalia no período analisado em questão. A maior prevalência dos casos $59,23 \%(N=587)$ ocorreram na região nordeste, mais especificamente no estado da Bahia(BA) com 17,86\% ( $\mathrm{N}=177)$. Na análise de custos verificou-se que o custo da internação por microcefalia no Brasil foi de aproximadamente $R \$ 4.278 .176,73$ com a análise de sensibilidade baseada na 
variação de $+/-20 \%$, variando entre $R \$ 5.133 .812,07$ e $R \$ 3.422 .541,38$. A microcefalia por ser uma doença que ocasiona uma série de dependências e alterações psicomotoras, gera muitos custos para o governo e para as famílias dos acometidos, se configurando como um grave problema de saúde pública e atingindo um alto percentual populacional diante da incidência das infecções ocasionas pelo vírus Zika.

Palavras-Chave: Microcefalia, Vírus Zika, Epidemiologia, Custos. 


\section{SUMÁRIO}

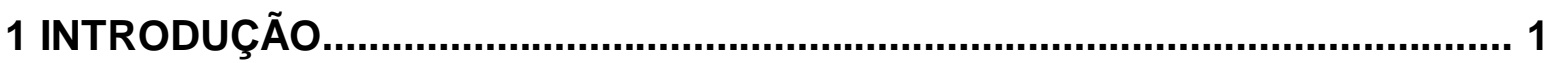

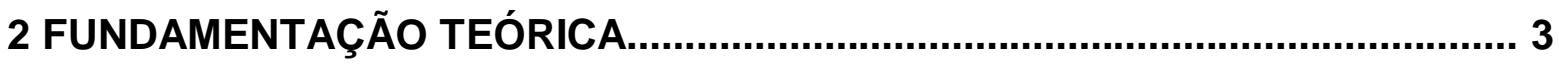

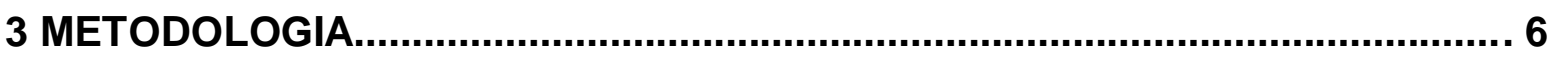

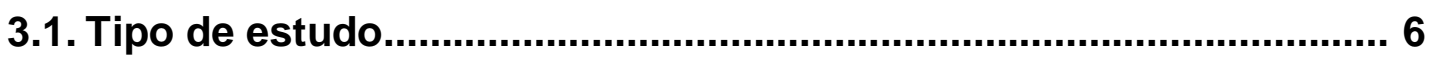

3.2. Área e período de estudo.............................................................. 6

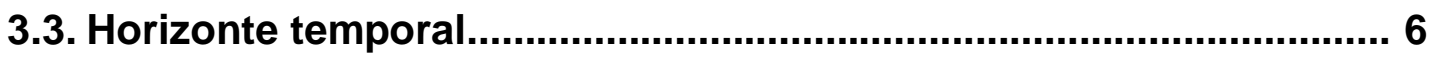

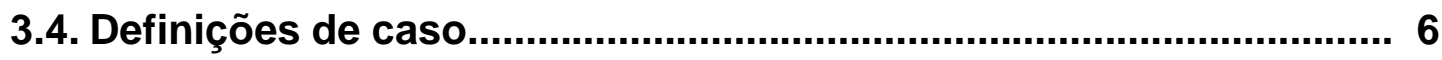

3.5. Análise epidemiológica dos dados................................................... 7

3.6. Perspectiva da análise de custos................................................... 7

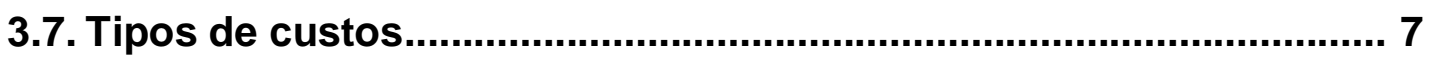

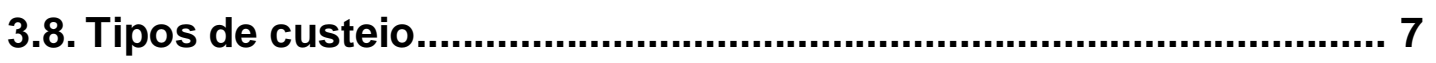

3.9. Modelo analítico de custos da doença................................................ 7

3.10. Fontes de dados............................................................................. 7

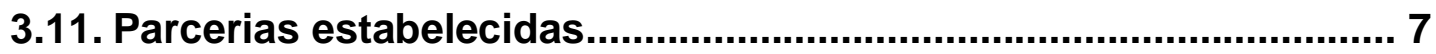

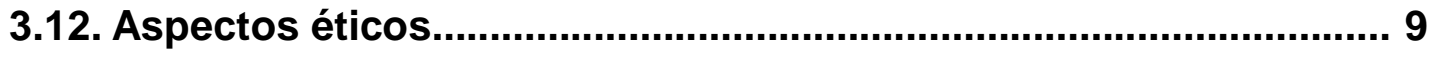

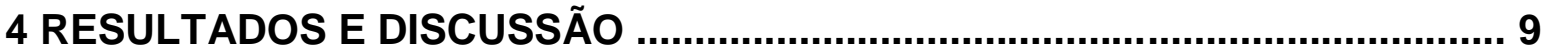

4.1 Análise epidemiológica dos casos de microcefalia no ano de 2016 ..9

4.2 Analise dos custos diretos por internação de microcefalia derivada

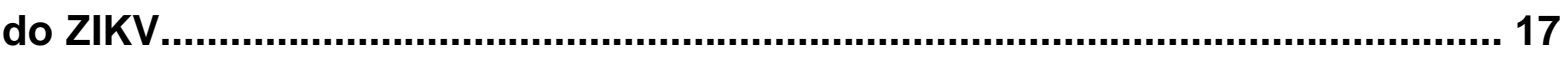

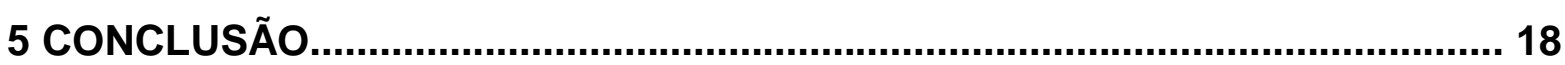

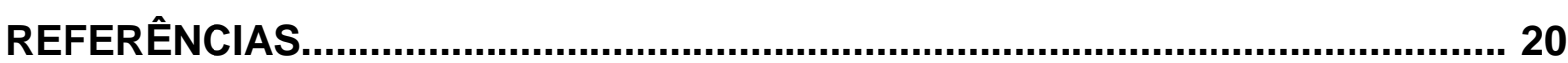




\section{INTRODUÇÃO}

A microcefalia decorre de anomalias congênitas ou pode ter origem após o parto, ocasionando alterações de estrutura e/ou de função do Sistema Nervoso (BRASIL, 2015). O processo causal da microcefalia é constituído de múltiplos e variados fatores, tais como: substancias teratogênicas, alterações cromossômicas e diversas infecções congênitas (MARINHO et al., 2016).

A microcefalia ocasionada pelo ZIKA vírus (ZIKV) foi detectada após o surto de microcefalia em Pernambuco, e a partir deste foi feita a relação entre o vírus e a patologia, ainda não se sabe ao certo o mecanismo que gera a morbidade no feto, no entanto sabe-se que a transmissão é vertical e as alterações morfofisiológicas variam de acordo com a idade gestacional com que a gestante é acometida pelo ZIKV (REIS, 2015).

O ZIKV é um arbovírus da família Flaviviridae e gênero Flavivirus. Na mesma família estão os vírus que causam a dengue, a febre amarela e o vírus do Nilo Ocidental (PINTO JUNIOR et al., 2015; SAMPATHKUMAR; SANCHEZ, 2016; PETERSEN et al. , 2016). A transmissão do ZIKV ocorre por meio da picada dos mosquitos do gênero Aedes durante o dia; esses artrópodes encontram-se em grande número nas zonas tropicais e subtropicais. Outras formas de transmissão são por via sexual, perinatal e hemotransfusão, porém ainda não há evidências da contribuição dessas formas de transmissão para epidemias (PINTO JUNIOR et al., 2015; SAMPATHKUMAR; SANCHEZ, 2016).

As gestantes podem ser infectadas pelo ZIKV em todos os trimestres e os sintomas são semelhantes aos apresentados pelos demais pacientes da população geral. A transmissão vertical do ZIKV ocorre ao longo da gestação e as consequências fetais incluem: microcefalia, atrofia cerebral, dilatação ventricular e calcificações intracranianas entre outros (MEANEY-DELMAN et al., 2016). As vias de transmissão perinatal prováveis são: pela placenta, no parto e durante aleitamento (BESNARD et al., 2014). Os principais sintomas incluem; febre baixa ou alta, podendo atingir $39^{\circ} \mathrm{C}$, mialgia, dores articulares que acometem as mãos, joelhos e tornozelos, dor lombar e conjuntivite sem secreção purulenta. Os pacientes também podem manifestar anorexia, náuseas, vômitos, vertigem e dor retro orbital (PINTO JUNIOR et al., 2015). 
Ainda não há vacinas ou medicamentos antivirais específicos para o tratamento da doença, o tratamento objetiva apenas o alívio dos sintomas (PINTO JUNIOR et al., 2015). A prevenção da infecção pelo ZIKV pode ser feita principalmente por meio de erradicação dos possíveis criadouros dos mosquitos Aedes aegypti. Além do uso de repelentes, roupas claras que cobrem todo o corpo, mosquiteiros e preservativo para evitar uma provável transmissão (ORGANIZAÇÃO MUNDIAL DA SAÚDE, 2016).

Atualmente, o ZIKV é considerado um vírus emergente de grande importância mundial devido principalmente à magnitude de suas complicações (ZANLUCA; SANTOS, 2016). Em junho de 2015 os casos neurológicos associados à doença exantemática foram identificados na região onde Zika, Dengue e Chikungunya estavam presentes e ao fim do mesmo mês, o Ministério da Saúde (MS) recomendou a notificação imediata das síndromes neurológicas. No fim de setembro de 2015, o Brasil registrou os primeiros casos de microcefalia potencialmente associados ao ZIKV no Estado de Pernambuco. Em outubro, em decorrência do aumento abrupto da incidência de microcefalia em relação aos anos anteriores, o MS notificou a Organização Mundial da Saúde (OMS) (HEUKELBACH et al., 2016).

A OMS declarou diante das evidencias uma emergência de saúde pública de preocupação internacional no dia $1^{\circ}$ de fevereiro de 2016. A relação com acometimentos neurológicos e anomalias congênitas vem confirmando-se no Brasil, mas a investigação continua em andamento (HEUKELBACH et al., 2016).

Estima-se que cada caso de microcefalia representa uma perda de 29,95 DALYs (Anos de vida ajustado por incapacidade, do inglês Disability ajusted life years) e um custo médico direto de US\$91.102,00 (ALFARO-MURILLO, 2016).

A presente pesquisa tem como objetivo conhecer os custos diretos e os dados epidemiológicos relacionados à microcefalia em recém-nascidos causada pelo ZIKV no Brasil no ano de 2016, considerando esses dados essenciais para um completo diagnóstico dos efeitos da epidemia no cenário brasileiro. 


\section{REVISÃO BIBLIOGRÁFICA}

A microcefalia é uma condição rara onde o Recém-Nascido (RN) apresenta uma cabeça pequena ou em que a cabeça deixa de crescer após o nascimento. Para saber se um RN tem microcefalia é preciso medir a circunferência da cabeça 24 horas depois do nascimento, comparando o valor com os padrões de crescimento da OMS e continuar a medir o seu crescimento durante a primeira infância. Não existem testes específicos para determinar se um RN irá nascer com microcefalia, porem a utilização da ecografia no terceiro trimestre de gravidez pode identificar o problema. Os RN com microcefalia podem desenvolver convulsões e sofrer problemas físicos ou de aprendizagem à medida que crescem. Existem muitas causas possíveis de microcefalia entre algumas estão exposição a substâncias químicas, anomalias genéticas, mal nutrição grave durante a vida do feto e infecções (WORLD HEALTH ORGANIZATION, 2016).

O ZIKV foi incialmente identificado em 1947 na floresta de Zika perto da Entebbe, localizada em Uganda, por meio de uma amostra de soro de um macaco Rhesus obtido durante um estudo sobre a febre amarela. Estudos filogenéticos do genoma viral revelaram a existência desse vírus na região desde 1920. Os casos iniciais da infecção por ZIKV em seres humanos ocorreram em Uganda no ano de 1952. O vírus foi detectado em outros países africanos nas décadas seguintes, como na Nigéria, em 1960 , onde foram detectadas sorologias positivas. Outros países que tiveram evidências de infecção sorológicas e virologias foram, Senegal, Gabão, Serra Leoa, Costa do Marfim, Tanzânia, Egito, Gabão e em países da África Central. (PINTO JUNIOR et al., 2015; SAMPATHKUMAR; SANCHEZ, 2016; PETERSEN et al., 2016).

A presença do ZIKV fora da continente Africano foi registrada na Indonésia entre 1977 e 1978, quando anticorpos contra o vírus foram detectados no soro de 30 pacientes. Houve epidemias na Federação dos Estados da Micronésia na ilha de Yap na última década (2007), sendo esse primeiro foco fora da África e da Ásia. O ZIKV espalhou-se pelas ilhas do Oceano Pacifico e em outubro de 2013 ocorreram os primeiros casos na Polinésia Francesa (PF) que culminaram em uma epidemia com 19.000 casos suspeitos e 284 casos confirmados. Os primeiros casos nas Américas ocorreram em fevereiro de 2014 na llha de Páscoa, possivelmente decorrentes do surto na Micronésia e na PF. No Brasil, os primeiros casos foram confirmados no Nordeste do Brasil, em 2015 (PINTO JUNIOR et al., 2015). 
Os dados analisados retrospectivamente na Polinésia Francesa após os casos de microcefalia no Brasil revelaram várias anomalias do sistema nervoso central dos recém-nascidos, semelhantes aos casos identificados no Brasil (BESNARD et al., 2014). Embora o ZIKV tenha sido descrito pela primeira vez na década de 1940, só recentemente vem se constituindo como um grave problema de saúde pública. Desde seu reaparecimento em 2007 até março de 2016, já foram descritos casos autóctones em 52 países e territórios, principalmente nas Américas (BROUTET et al., 2016; PETERSEN et al., 2016).

No estado de Pernambuco, no fim de outubro de 2015, foi detectado a presença de IgM específica de ZIKV em amostras de sangue e líquido cefalorraquidiano de neonatos com microcefalia. Indicando que eles tinham uma infecção congénita por ZIKV. Constituindo uma evidência de que a microcefalia foi uma consequência da infecção pelo ZIKV (CORDEIRO et al., 2016). Em estudo realizado com 345 mulheres no Rio de Janeiro, 182 mulheres (53\%) tiveram resultado positivo para ZIKV no sangue, urina ou ambos. Entre 117 recém-nascidos vivos, 42\% apresentaram achados clínicos ou cerebrais anormais ou ambos, incluindo 4 crianças com microcefalia. O estudo evidenciou que a infecção por ZIKV durante a gravidez é deletéria para o feto e está associada à morte fetal, restrição de crescimento e anormalidades do sistema nervoso central (BRASIL, 2016b). Também foi encontrado ZIKV no tecido cerebral de um feto com microcefalia, sua mãe adquiriu o vírus quando estava no Brasil, mostrando associação grave de lesão cerebral com infecção por ZIKV e transmissão vertical (MLAKAR et al., 2016).

Em animais foi demonstrado que o ZIKV infecta fetos de camundongos, causando restrição do crescimento intrauterino, incluindo sinais de microcefalia. Além disso, o vírus infecta células progenitoras corticais humanas, levando ao aumento da morte celular. Estes resultados indicam que a ZIKV cruza a placenta provocando microcefalia e prejuízo no neurodesenvolvimento (CUGOLA et al., 2016). Avaliando os dados disponíveis é possível concluir que existe uma relação causal entre a infecção pré-natal pelo ZIKV e a microcefalia e outras anomalias cerebrais graves (RASMUSSEN et al., 2016).

Até 31 de dezembro de 2016, 10.867 casos de microcefalia e/ou alterações do Sistema Nervoso Central foram notificados no RESP-Microcefalia. Desses, 2.366 confirmados e 49 prováveis. Dos casos confirmados, os estados da Bahia e Pernambuco foram os com maior número, 433 e 408 casos, respectivamente. Do total 
de 10.867 casos notificados, 582 (5,3\%) evoluíram para óbito fetal ou neonatal. Dos 582 óbitos notificados, 200 (34,4\%) foram confirmados, 5 (0,9\%) foram classificados como prováveis. Sendo os estados da Bahia, Ceará e Rio Grande do Norte com maior número de casos confirmados 34, 25 e 23 casos, respectivamente (BRASIL, 2017).

Diante deste contexto o ministério da saúde desenvolveu diretrizes com a finalidade de capacitar os profissionais de saúde a realizarem um acompanhamento efetivo dirigido às crianças e famílias afetadas. Essa medida propões uma assistência integral e longitudinal aos envolvidos, provendo uma estimulação precoce com 0 objetivo potencializar o desenvolvimento neuropsicomotor das crianças com alteração neurológicas e apoiar as famílias (BRASIL, 2016a).

Além dos dados epidemiológicos relatados, os estudos de carga de doença têm agregado, nas últimas décadas, as estimativas dos custos envolvidos no adoecimento, nas sequelas e nas mortes, sob a perspectiva tanto dos sistemas de saúde quanto da sociedade. A perspectiva da sociedade incorpora custos indiretos por perda de produtividade relacionada ao adoecimento e mortes (DRUMMOND; MCGUIRE, 2006).

Os estudos de custo da doença ao traduzirem a magnitude da doença em termos econômicos, auxiliam a reflexão sobre o quanto a sociedade tem sido onerada pela condição investigada, além de fornecer subsídios para outras investigações (RICE, 2000), como as de custo-efetividade.

Os custos devem ser estimados a partir de valores efetivamente desembolsados no período de análise, devendo ser identificados e quantificados todos os insumos utilizados na produção do serviço ou do procedimento prestado. Custos com os medicamentos, recursos diagnósticos e terapêuticos, além do pagamento dos profissionais envolvidos, devem ter seu valor monetário aferido ou estimado, explicitando-se o período de base e os métodos utilizados (BRASIL, 2014). 


\section{METODOLOGIA}

\subsection{Tipo de estudo}

Foram realizados os seguintes estudos:

- Estudo epidemiológico descritivo de casos de microcefalia no Brasil;

- Avaliação econômica parcial do tipo custo de doença, baseado nos custos hospitalares da microcefalia associados ao ZIKV no Brasil.

\section{2. Área e período de estudo}

Todos os estados brasileiros que notificaram casos de microcefalia relacionados ao ZIKV em 2016.

\subsection{Horizonte temporal}

O estudo analisou os dados epidemiológicos e considerou os custos da hospitalização associados à microcefalia por ZIKV ocorridos no período de um ano.

\subsection{Definições de caso}

Neonato diagnosticado com microcefalia, possivelmente, associada à infecção por ZIKV durante a gestação de acordo com os critérios estabelecidos pelo MS na nota informativa $\mathrm{n}^{0}$ 01/2015 - COES microcefalias:

- Recém-nascido, entre 37 e 42 semanas de gestação, com perímetro cefálico aferido ao nascimento igual ou menor que $33 \mathrm{~cm}$, na curva da OMS; ou

- Recém-nascido, menor que 37 semanas de gestação, com perímetro cefálico aferido ao nascimento, menor ou igual que o percentil 3 (dois desvios padrão) na curva de Fenton.

\subsection{Análise epidemiológica dos dados}

Dados epidemiológicos foram obtidos e analisados com o objetivo de subsidiar a descrição dos casos registrados de microcefalia associados ao ZIKV no Brasil e de fornecer parâmetros para o cálculo dos custos.

A análise epidemiológica dos dados está no escopo da estatística descritiva, que é uma modalidade da estatística que representa conjunto de técnicas que tem a finalidade de descrever, resumir, totalizar, e apresentar graficamente dados de pesquisa. Nesse estudo a análise de dados seguiu as seguintes etapas: 
a) Organização dos dados em planilha de Microsoft Excel, versão 2010 e aplicativo SPSS (versão 20), a partir de dados coletados nas diversas fontes;

b) Categorização e classificação dos dados baseadas nas variáveis de interesse.

c) Codificação dos dados; para cada categoria foi atribuído um valor numérico;

d) Apresentação dos dados em tabelas ou figuras e fazer a sua interpretação o que inclui o relato dos resultados.

\subsection{Perspectiva da análise de custos}

Este estudo foi desenvolvido sob a perspectiva do SUS.

\subsection{Tipos de custos}

Foram estimados os custos diretos médicos relacionados à assistência hospitalar.

\subsection{Tipos de custeio}

O estudo utilizou a técnica do macrocusteio (gross-costing ou top-down) para obter os custos médio associados à hospitalização de recém-nascidos com microcefalia (serviços profissionais e hospitalares) com base no SIH/SUS. O referido custo foi multiplicado pela estimativa do total de casos em todo território nacional, possibilitando a obtenção do custo total da microcefalia associada ao ZIKV.

\subsection{Fontes de dados}

Para subsidiar o custo médio da hospitalizaçãoao custeiofoi utilizado o Sistema de Informação Hospitalar Descentralizados (SIH/SUS), Os dados epidemiológicos foram obtidos a partir da da análise dosRegistros de Eventos em Saúde Pública (RESP).

\subsection{Parcerias estabelecidas}

O presente projeto contribuiu com dois grandes projetos denominados "Carga da doença e Custos da infecção pelo vírus Zika no Brasil" e "História natural da infecção pelo vírus Zika no Distrito Federal", ambos desenvolvidos a partir de parceria científica estabelecida entre o Centro Universitário de Brasília (UniCEUB) e a Universidade de Brasília (UnB). Assim, a pesquisa contou com a estrutura organizada 
pelas instituições envolvidas para a condução de ambas as pesquisas, facilitando a coleta e a análise dos dados necessários ao desenvolvimento da presente proposta. Ambos os projetos foram desenvolvidos por uma equipe multidisciplinar que contou com a presença do professor orientador e de pesquisadores de renomada reputação científica nacional e internacional.

\subsection{Aspectos éticos}

O presente projeto foi submetido e aprovado pelo comitê de Ética e Pesquisa do UniCEUB (Parecer no 1.793.931), obedecendo as normas da Resolução 466/2012 do Conselho Nacional de Saúde, que regulamenta a pesquisa envolvendo seres humanos. Este estudo foi realizado em consonância com as diretrizes metodológicas para Estudos de Avaliação Econômica de Tecnologias em Saúde do Ministério da Saúde. A pesquisa utilizou dados publicados na literatura científica, dados de notificação de domínio público não nominais. Assim, não houve malefícios à população incluída no estudo. O estudo, potencialmente, proverá benefícios coletivos, uma vez que as informações que foram produzidas esclareceram aspectos econômicos e epidemiológicos importantes sobre a problemática em análise.

\section{RESULTADOS E DISCUSSÃO}

\subsection{Análise epidemiológica dos casos de microcefalia no ano de 2016}

Após análise de dados do Registro de Eventos em Saúde Pública (RESP) de 2016 foi possível detectar um quantitativo de 991 casos, entre estes prováveis e confirmados, de microcefalia ocasionada pelo vírus Zika no Brasil. Deste grupo sabese que a distribuição geográfica teve uma maior incidência na região Nordeste com $59,29 \%(n=587)$, em segundo lugar com 20,99\% $(n=208)$ dos casos ficou a região Sudeste. Já a região Centro-oeste representou $9,79 \%(n=97)$ da incidência, a região Norte teve $7,97 \%(n=79)$ de afetados, e por último a região Sul que obteve $2,02 \%(n=$ 20) de acometidos (Figura 1).

Segundo BRASIL, 2017 a maior incidência de casos de infecção pelo vírus Zika, no ano de 2016, se deu na região Centro-oeste, representando 59,9\% (219,2 casos/ 100 mil habitantes), no entanto é notório o destaque da região Nordeste que ficou com a segunda maior incidência brasileira apresentando 134,2 acometidos por 
100 mil habitantes, sendo importante enfatizar a ligação entre esses altos índices de casos de ZIKV, juntamente com o aumento de casos ocasionados pela microcefalia.

Ainda não há um consenso a respeito de como o ZIKV afeta a formação dos fetos em gestantes, no entanto estudos relatam a presença do RNA vírus tanto no liquido amniótico de gravidas acometidas, como no cérebro de recém-nascidos acometidos pela microcefalia (KAUER et al,2017; MLAKAR, et al;2016), outro indício importante é o aumento da prevalência de casos de microcefalia culminados com a alta taxa de infecções pelo vírus Zika demonstrados anteriormente.

Figura 1- Distribuição geográfica de casos confirmados e prováveis de microcefalia pelo vírus Zika, por regiões geográficas, no ano de 2016.

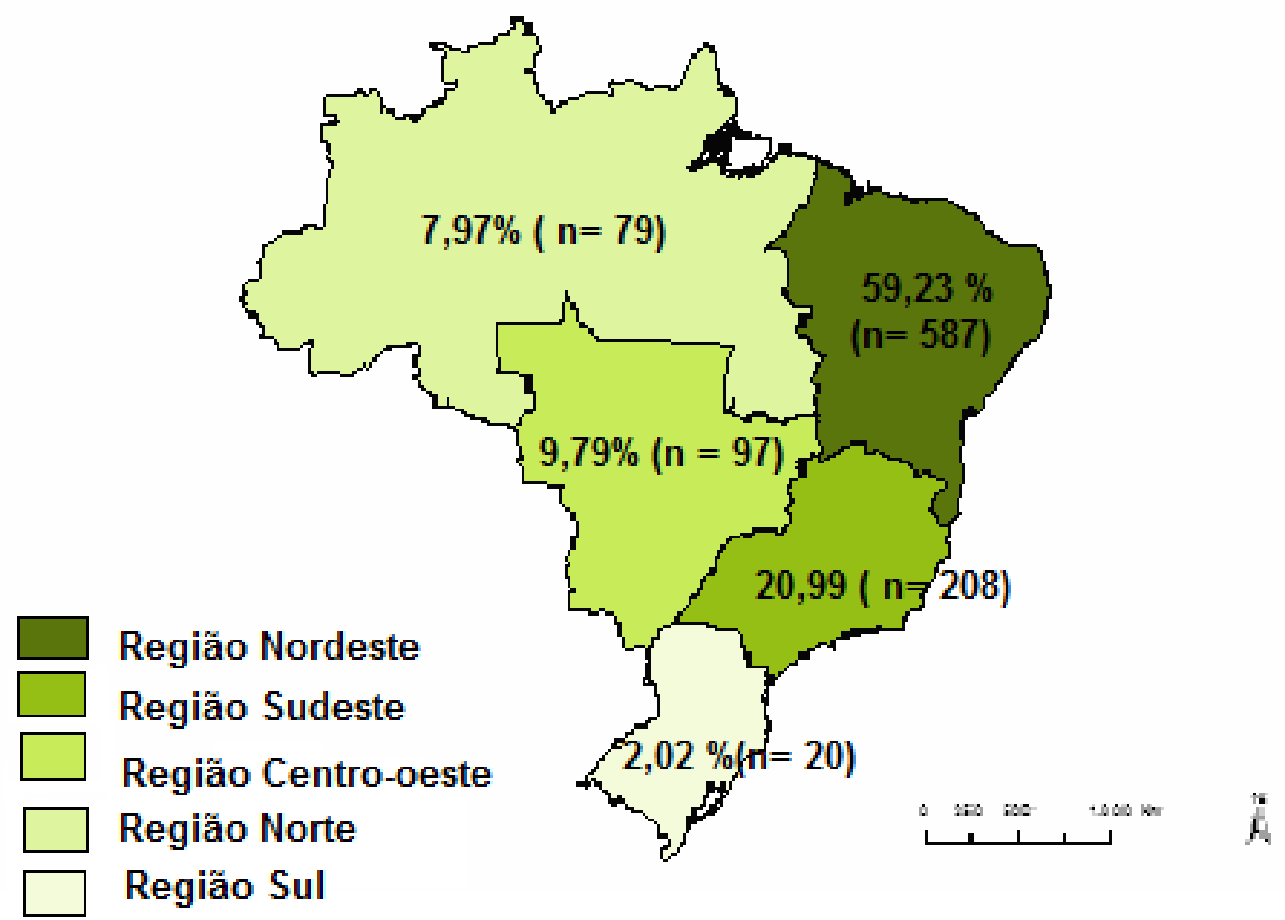

Fonte: Extraído, adaptado e organizado de RESP, 2016.

Outra distribuição importante foi em relação às unidades federativas do Brasil, onde o estado da Bahia se destacou representando 17,86\% ( $n=177)$ acometidos pela microcefalia ocasionada por ZIKV, além do Rio de janeiro que apresentou 10,9\% $(n=108)$ dos casos. Dos nove estados mais incidentes foi analisado que todos pertencem ou a região Nordeste ou a Sudeste, sendo a maior prevalência da região Nordeste enfatizando a incidência de distribuição de casos por região (Tabela 1). 
Entre os estados do Brasil com maior incidência de casos prováveis de acometidos por ZIKV se destacou no ano de 2016 o Mato Grosso (670,5 casos/100 mil habitantes), Rio de Janeiro (407,7 casos/100 mil habitantes) e a Bahia (338,5 casos/100 mil habitantes) que se caracteriza como o estado com maior número de casos de microcefalia (BRASIL, 2017).

Diante desses dados é importante ressaltar que os casos de microcefalia foram perceptíveis no Brasil inicialmente na região Nordeste, mas especificamente em Pernambuco, seguindo da identificação tanto no Rio Grande do Norte e na Bahia (LOWE,2018), enfatizando que na época de analise dos dados no RESP esses estados tinham um alto quantitativo de ZIKV e aumento gradual de acometidos por microcefalia que se caracterizam também pela detecção dessa nova associação.

Tabela 1 - Casos de microcefalia por vírus Zika por unidade federativa

\begin{tabular}{lcc}
\hline \multicolumn{1}{c}{ Unidade federativa } & $\mathbf{f}$ & $\%$ \\
\hline Bahia (BA) & 177 & 17,86 \\
Rio de Janeiro (RJ) & 108 & 10,90 \\
Pernambuco (PE) & 99 & 9,99 \\
São Paulo (SP) & 66 & 6,66 \\
Alagoas (AL) & 61 & 6,16 \\
Ceara (CE) & 56 & 5,65 \\
Paraíba (PB) & 55 & 5,55 \\
Piauí (PI) & 42 & 4,24 \\
Rio Grande do Norte (RN) & 35 & 3,53 \\
Mato Grosso (MT) & 33 & 3,33 \\
Sergipe (SE) & 33 & 3,33 \\
Goiás (GO) & 29 & 2,93 \\
Maranhão (MA) & 29 & 2,93 \\
Amazonas (AM) & 24 & 2,42 \\
Mato Grosso do Sul (MS) & 21 & 2,12 \\
Espirito Santo (ES) & 18 & 1,82 \\
Minas Gerais (MG) & 16 & 1,61 \\
Rio Grande do Sul (RS) & 16 & 1,61 \\
Rondônia (RO) & 16 & 1,61 \\
Roraima (RR) & 15 & 1,51 \\
Distrito Federal (DF) & 14 & 1,41 \\
Pará (PA) & 14 & 1,41 \\
Tocantins (TO) & 6 & 0,61 \\
Amapá & 4 & 0,40 \\
Santa Catarina (SC) & 4 & 0,40 \\
\hline \multicolumn{1}{c}{ Total } & $\mathbf{9 9 1}$ & $\mathbf{1 0 0}$ \\
\hline
\end{tabular}

Fonte: Extraído, adaptado e organizado de RESP, 2016. 
O vírus Zika por ter sintomas parecidos com outras doenças infecciosas causadas por arboviroses, como a dengue e a chikungunya, pode ter seu diagnostico dificultado (MUSSO, GUBLER; 2016) consequentemente seu diagnostico pode ser distorcido, ainda mais diante do contexto brasileiro, onde as condições climáticas são favoráveis a essas arboviroses.

De modo que a detecção de casos por ZIKV é um processo complexo, pois a sintomatologia da doença influencia como já citado, além disso, por ser uma doença que teve surtos recentes, seu diagnostico também veio se desenvolver com mais especificidade recentemente, outro fator relevante é a respeito dos pacientes assintomáticos que representam uma parcela considerável dos acometidos (LOURENÇO, et al; 2017).

Pensando no âmbito da microcefalia ocasiona pelo ZIKV essa detecção se torna mais complexa, por ter que haver um duplo diagnostico, tanto da gestante acometida pelo vírus, como da criança com a presença da microcefalia. Segundo os dados coletados encontramos que das gestantes que obtiveram a detecção da infecção pelo vírus zika realizada durante a gestação $55,17 \%(n=16)$ dos casos de microcefalia foram captados intrauterinamente, $41,38 \%(n=12)$ dos acometidos foram descobertos no pós-parto e 3,45\%(n=1) não foram detectados, não havendo casos ignorados. Totalizando assim 29 casos de detecção de gestantes com a infecção pelo vírus Zika durante a gravidez (Tabela 2).

Já as gestantes que tiveram diagnostico de ZIKV no pós-parto, a microcefalia foi identificada $57,80 \%(n=556)$ no pós-parto também, sendo que $30,77 \%(n=296)$ foi captada em fase intrauterina $11,33 \%(n=109)$ dos casos tiveram diagnostico ignorado e $0,10 \%(n=1)$ não foi identificado, totalizando assim 962 casos de identificação de infecção pelo Zika em gestante no pós-parto. Pensando de maneira geral temos que do recém-nascido acometidos pela microcefalia $57,32 \%(n=568)$ foram captados no pós-parto, $31,48 \%(n=312)$ foi no meio intrauterino, $11 \%(n=109)$ dos casos foram ignorados esse diagnóstico e 0,20\%( $n=2)$ não detectados (Tabela 2)

Esses dados evidenciam o rastreamento dessas gestantes infectadas pelo ZIKV e dos recém-nascidos afetados demonstrando uma possível subnotificação, sendo importante se atentar ao fato que a maioria das gestantes foram testadas para infecção no período pós-parto, onde o recém-nascido já havia apresentado sinais da microcefalia, segundo a sintomatologia da doença (WORLD HEALTH ORGANIZATION, 2016). Além do fato da maioria dos recém-nascidos terem sido 
diagnosticados apenas após o nascimento. De modo que é notável um atraso na detecção e notificação destes casos diante os dados.

No entanto é importante salientar que no período de analise, a correlação de ambas as afecções era algo novo para a comunidade científica e para os profissionais de saúde, não haviam parâmetros bem estabelecidos e não se sabia ao certo até que ponto o ZIKV influenciava no acometimento de microcefalia nas crianças(LOWE et al; 2018) .

Tabela 2 - Casos de microcefalia pelo Zika vírus por momento de detecção do vírus em gestantes pós-parto, em gestantes infectadas durante a gestação e a notificação geral dos casos:

\begin{tabular}{|c|c|c|}
\hline $\begin{array}{l}\text { Microcefalia por gestantes com } \\
\text { ZIKV de detecção durante a } \\
\text { gestação }\end{array}$ & $\mathbf{f}$ & $\%$ \\
\hline Intrauterino & 16 & 55,17 \\
\hline Pós- parto & 12 & 41,38 \\
\hline Não detectada & 1 & 3,45 \\
\hline lgnorado & 0 & 0 \\
\hline Subtotal & 29 & 2,92 \\
\hline \multicolumn{3}{|c|}{ Microcefalia por gestantes com ZIKV de detecção pós- parto } \\
\hline Pós- parto & 556 & 57,80 \\
\hline Intrauterina & 296 & 30,77 \\
\hline Ignorado & 109 & 11,33 \\
\hline Não detectado & 1 & 0,10 \\
\hline Subtotal & 962 & 97,08 \\
\hline \multicolumn{3}{|c|}{ Momento de detecção da microcefalia geral } \\
\hline Pós- parto & 568 & 57,32 \\
\hline Intrauterina & 312 & 31,48 \\
\hline Ignorado & 109 & 11 \\
\hline Não detectado & 2 & 0,20 \\
\hline Total & 991 & 100 \\
\hline
\end{tabular}

Fonte: Extraído, adaptado e organizado de RESP, 2016.

As gestantes acometidas pela infecção do vírus Zika analisadas por meio da base de dados se caracterizam por serem em grande parte da raça/cor parda representando assim 49,24\% $(n=488)$ dos casos, ficando a raça/cor branca em segundo lugar com $13,42 \%(n=133)$ de afetadas, há ainda com baixas incidências a raça/cor negra com $6,16 \%(\mathrm{n}=61)$, a raça/cor indígena com $1,11 \%(\mathrm{n}=11)$ e a amarela com $0,91 \%(n=9)$ de representatividade. Sendo importante ressaltar que $29,16 \%(n=289)$ dos casos não possuíam essa informação (Tabela 3 ). 
Em relação à sintomatologia da infecção durante a gestação os valores são próximos e revelam pouca discrepância entre as gravidas que apresentaram sintomas $50,96 \%(n=505)$ e as assintomáticas $49,04 \%(n=486)$. Já em relação aos exames efetuados apenas $10,8 \%(n=107)$ revelaram positividade para o vírus, $7,37 \%(n=73)$ teve resultado negativado ou não reagente e $1,61 \%$ ficaram indetectáveis. No entanto a incidência maior foi de casos de exames ignorados com $55,3 \%(n=548)$, sendo que ainda houve um alto numero de exames não realizados representando 24,92\%( $n=247)$ destes(Tabela 3)

O momento de diagnostico da infecção que afetou o feto gerando microcefalia neste também é importante para ter-se a margem de captação de casos que realmente foram ocasionados pelo Zika vírus, diante dos dados tem-se que $97,07 \%(n=962)$ foram captadas no pós-parto, tendo se assim um diagnostico tardio da infecção e apenas 2,93\%( $n=29$ ) durante a gestação.

Tabela 3 - Dados das gestantes atingidas pelo vírus zika por raça/cor, presença de sintomatologia, resultados de exames e momento de diagnóstico:

\begin{tabular}{lcc}
\hline Raça/cor & $\mathbf{f}$ & $\%$ \\
\hline Parda & 488 & 49,24 \\
Sem informação & 289 & 29,16 \\
Branca & 133 & 13,42 \\
Negra & 61 & 6,16 \\
Indígena & 11 & 1,11 \\
Amarela & 9 & 0,91 \\
\hline Sintomas durante a gestação & \\
\hline Não & 486 & 49,04 \\
Sim & 505 & 50,96 \\
\hline Resultado dos exames de deteç̧ão laboratoriais & \\
\hline Ignorado & 548 & 55,3 \\
Não realizado & 247 & 24,92 \\
Reagente/Positivo & 107 & 10,8 \\
Não reagente /Negativo & 73 & 7,37 \\
Indetectável/Indeterminado & 16 & 1,61 \\
\hline Momento do diagnóstico de Zika vírus & \\
\hline Pós- parto & 962 & 97,07 \\
Durante a gestação & 29 & 2,93 \\
\hline Total & $\mathbf{9 9 1}$ & $\mathbf{1 0 0}$ \\
\hline
\end{tabular}

Fonte: Extraído, adaptado e organizado de RESP, 2016.

O fator da raça/cor das gravidas pode estar relacionada a localidade de maior incidência de infecções pelo ZIKV. Segundo IBGE,2010 cerca de 59,44\% da população da região Nordeste é da raça/cor parda, já na região Sudeste sabe-se que 
$35,69 \%$ da população apresenta esta raça/cor. E estudos relatam que as afecções não tem correlações de sintomatologia e gravidade referentes a raça/cor dos acometidos (MUSSO,GUBIER;2016).

A sintomatologia apresentada pelas gestantes como já citado não teve grandes discrepâncias, neste item é importante salientar o alto índice de casos assintomáticos que ocasionam o disseminação do vírus, afetam as gestante e seus fetos e podem vir a não ser detectados por conta de dificuldade de rastreamento e diagnóstico correto da doença (HABY et al; 2018).

Outro fator importante levantado na tabela é o alto índice de resultados ignorados de exames de detecção, o que dificultam uma análise mais fidedigna a respeito de como foram os diagnósticos laboratoriais destas gestantes, além da alta incidência de exames não realizados.

Como meio de diagnostico para a microcefalia temos que dos casos prováveis a maior incidência de método diagnostico foi o de imagem com $97 \%(n=30)$ da frequência, sendo que dos analisados $3 \%(n=1)$ não foi informado por qual meio se teve o diagnóstico. Já dos casos confirmados se destaca o diagnóstico de imagem com $65 \% \quad(n=624)$ de incidência, em segundo lugar temos o laboratorial representando $26,25 \%$ ( $n=252)$ da totalidade, o clínico epidemiológico se estabelece como menor frequência com apenas 2,81\% $(n=27)$ dos casos, além disso, 5,94\% $(n=57)$ dos casos não foram informados o meio diagnostico (Gráfico 1 ).

\section{Gráfico 1- Proporção de métodos de confirmação diagnostica para microcefalia:}

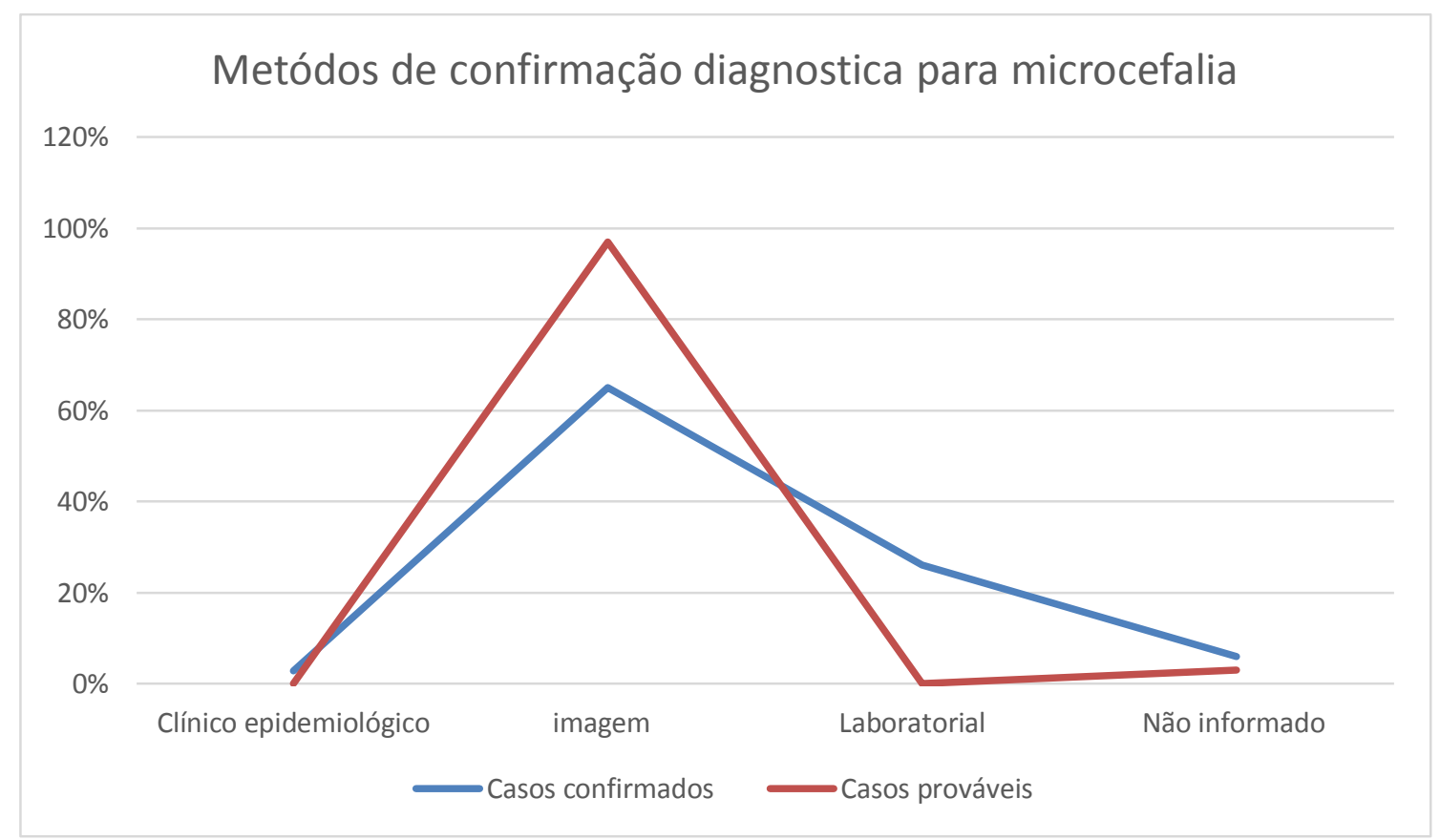

Fonte: Extraído, adaptado e organizado de RESP, 2016. 
O diagnóstico para microcefalia normalmente se baseia inicialmente em diagnósticos clínicos, onde a criança apresenta redução do perímetro cefálico, no entanto é importante a realização de diagnósticos de imagem para confirmação deste. No caso dessa doença o diagnóstico laboratorial influencia na detecção da dupla afecção (BRASIL,2015). Ao observar os dados pode notar-se nos registros o alto proporção de exames de imagem que são o que realmente captam as alterações das estruturas neurológicas da microcefalia (ARAGÃO, et al;2016).

Ao realizar uma análise acerca dos nascidos-vivos detectados e registrados no banco de dados como casos prováveis ou confirmados de microcefalia foi notável que $84,16 \%$ ( $n=834)$ dos acometidos nasceram com idade gestacional a termo, $14,13 \%(n=140)$ pré-termo e $1,51 \%(n=15)$ pós-termo e $0,2 \%(n=2)$ não foram informados, demonstrando que apesar do desenvolvimento da microcefalia no feto 0 curso da gestação não foi afetado (tabela 4).

Já em relação ao sexo a distinção entre os acometidos foi relativamente baixa, sendo que $53,88 \%(n=534)$ são meninas e $44,90 \%(n=445)$ são meninos e em $1,21 \%$ dos casos esse dado foi ignorado. Outro fator importante detectado foi o peso dos recém-nascidos ao nascer $54,89 \%(n=544)$ apresentando peso normal; 36,93\%( $\mathrm{n}=366)$ baixo peso e apenas $0,3 \%(\mathrm{n}=3)$ estavam acima do peso, destes dados $7,87 \%(n=78)$ foram ignorados.

Tabela 4- Dados dos nascidos-vivos atingidos pela microcefalia ocasionada pelo vírus zika por idade gestacional, sexo e peso ao nascer:

\begin{tabular}{lcc}
\hline Idade gestacional & $\mathbf{f}$ & $\%$ \\
\hline Termo & 834 & 84,16 \\
Pré-termo & 140 & 14,13 \\
Pós-termo & 15 & 1,51 \\
Não informado & 02 & 0,20 \\
\hline Sexo & & \\
\hline Meninas & 534 & 53,88 \\
Meninos & 445 & 44,90 \\
Innorados & 12 & 1,21 \\
\hline Peso ao nascer & & \\
\hline Normal (2500g- 3999g) & 544 & 54,89 \\
Baixo peso (100g- 2499g) & 366 & 36,93 \\
Acima do peso (4000g-8000g) & 03 & 0.30 \\
Ignorados & 78 & 7,87 \\
\hline Total & $\mathbf{9 9 1}$ & $\mathbf{1 0 0}$
\end{tabular}

Fonte: Extraído, adaptado e organizado de RESP, 2016. 
Outros estudos epidemiológicos não relataram uma correlação entre a idade gestacional e a incidência de microcefalia, em um deste foi detectado que o maior percentual era de casos a termo, com uma média de 38 semanas de gestação e estes nasceram em sua maioria de parto normal, com escala de Apgar alta( VARGAS,ESTIMA; 2016).

A microcefalia por ser uma alteração na formação do cérebro, gera mais modificações durante a gestação principalmente no primeiro trimestre desta, sendo que não há uma alteração segundo estudos evidenciadas na idade gestacional em que se inicia o parto e sim alterações de estruturas do feto, do que se sabe atualmente(NUNES, et al.2016).Ainda segundo estudo de VARGAS, ESTIMA; 2016 não houve distinções altas a respeito do sexo dos acometidos, assim como os dados aqui encontrados onde a discrepância é de apenas 8\%. Além disso o peso dos recémnascidos também teve sua mediana por volta de $2.628 \mathrm{~g}$, de modo que os casos estavam enquadrados no critério de peso normal (VARGAS, ESTIMA; 2016).

\subsection{Análise dos custos diretos por internação de microcefalia derivada do ZIKV}

$\mathrm{Na}$ análise de custos diante dos dados do Sistema de Informação Hospitalar (SIH) do SUS verificou-se um custo média de $\mathrm{R} \$ 4.317,03$ por internação ocasionada pela doença. De modo que unindo aos dados do RESP, 2016 que contava com 991 casos confirmados e prováveis, foi possível detectar que o custo de internação ocasionada pela microcefalia por ZIKV no Brasil, no ano de 2016, foi de e $R \$$ 4.278.176,73 com uma variação, de acordo com a análise de sensibilida,de, de $R \$$ 5.133.812,07 e R\$3.422.541,38.

Os custos diretos estão relacionados aos gastos do sistema de saúde inicial para com os acometidos pela microcefalia, para isso devido algumas limitações na pesquisa foi realizado o macrocusteio derivado das base de dados supracitadas.

$\mathrm{Na}$ análise de custos diretos o Programa de Nações Unidas para 0 desenvolvimento (PNUD) publicou um relatório com estimativas de custos ocasionados pelas infecções ocorridas pelo ZIKV. Nestes os autores discorrem que diante do do contexto epidemiológico na América latina e do Caribe entre 2015 e 2016, a estimativa de gastos foi de aproximadamente 7 a 18 bilhões de dólares. É importante 
salientar que está é uma visão mais amplificada, com um número mais abrangente de casos, além de considerar vários outros componentes de custos direto e indiretos..

Retomando aos dados encontrados na pesquisa em questão sabe-se que ao visualizar apenas os custos diretos da internação por microcefalia já se tem um dimensionamento a respeito do impacto econômico que essa doença teve no Brasil. Segundo as estimativas apenas de custos diretos em dois anos de acometidos pelo virus Zika será de aproximadamente USD 263.003.428, se for estimar a perda de produtividade chega-se a um acréscimo de USD 251.676.089. Pensando no âmbito apenas da microcefalia temos um custo médio durante a vida dos acometidos de aproximadamente USD 3.009.667.021(PNUD,2017). Indicando que esses dados aqui captura dos representam apenas um pequeno percentual dos custos totais de crianças com microcefalia no Brasil.

\section{Conclusão}

Diante do que foi detectado é perceptível a influência que a microcefalia ocasionada pelo ZIKV exerce diante a sociedade, seja por meio das implicações socioeconômicas, seja pelo impacto direto diante dos custos automáticos gerados pela morbidade.

A sociedade cientifica diante do surto de microcefalia buscou de todas as maneiras entender esse fenômeno e captar seus impactos, no entanto ainda há muito a ser descoberto e captado diante das alterações que essas crianças vão apresentar durante toda a sua vida, além disso é importante ressaltar o potencial do vírus para gerar outras alterações neurológicas que também modificam radicalmente a vida dos afetados.

A infecção pelo vírus Zika é um problema de saúde pública e isso já se é conhecido a muito tempo, no entanto ao se notar os principais locais de acometidos e diante da população que lá vive sabe-se que o impacto econômico nessas regiões de baixa-renda é bem maior, gerando uma problemática de famílias que não possuem o suporte econômico e do Sistema de Saúde Público suficientes para proporcionar uma boa qualidade de vidas aos seus filhos com morbidades, gerando assim crianças que não recebem estimulação precoce e atendimentos adequados . 
Os custos são de extrema importância pois além de demonstrar o quanto aquela doença impacta nas medidas que o governo deve estabelecer, salienta a respeito dos custos individuais de cada família, de cada profissional e de cada recémnascido acometido, servindo assim como uma maneira de demonstrar o quanto essa população precisa de mais visibilidade e programas de saúde acessíveis. Além de medidas de prevenção que sao fundamentais para o combate da doença, agora tornase necessário mais questionamentos e debates a respeito das medidas de recuperação dos acometidos.

Diante deste fato a presente pesquisa se configura como uma parcela de demonstração a respeito do impacto social ocasionado pela microcefalia pelo ZIKV no Brasil, no ano de 2016. No entanto ainda precisa haver muitos outros estudos que deem visibilidade para essa proporção da população que passa diariamente pelas barreiras sociais e econômicas ocasionadas pela doença. 


\section{REFERÊNCIAS}

ALFARO-MURILLO, Jorge A. et al. A cost-effectiveness tool for informing policies on Zika virus control. PLOS Neglected Tropical Diseases, San Francisco, v. 10, n. 5, p. 1-14, maio. 2016.

ARAGÃO, Maria De Fatima Vasco et al. Clinical Features and Neuroimaging (CT and MRI) Findings in Presumed Zika Virus Related Congenital Infection and Microcephaly: Retrospective Case Series Study." The British medical journal. V. 353, i1901. 2016.

BESNARD, M. et al. Evidence of perinatal transmission of Zika virus, French Polynesia, December 2013 and February 2014. Eurosurveillance, Stockholm, v. 19, n. 13, p. 1-4, abr. 2014.

BRASIL. Ministério da Saúde. Diretrizes metodológicas: diretriz de avaliação econômica, 2014. Disponível em: < http://bvsms.saude.gov.br/bvs/publicacoes/diretrizes_metodologicas_diretriz_avaliac ao_economica.pdf >. Acesso em: 21 abr. 2017.

BRASIL. Ministério da Saúde. Informe Epidemiológico $N^{\circ}$ 57-Semana Epidemiológica (SE) 52/2016 (25 A 31/12/2016) Monitoramento Dos Casos De Microcefalia No Brasil, 2017. Disponível em: < http://combateaedes.saude.gov.br/images/pdf/Informe-Epidemiologico-n57-SE52_2016-09jan2017.pdf >. Acesso em: 21 abr. 2017.

BRASIL. Ministério da Saúde. Protocolo de vigilância e resposta à ocorrência de microcefalia relacionada à infecção pelo vírus Zika, 2015. Disponível em: $<\quad$ http://portalsaude.saude.gov.br/images/pdf/2015/dezembro/09/Microcefalia--Protocolo-de-vigil--ncia-e-resposta---vers--o-1----09dez2015-8h.pdf >. Acesso em: 21 abr. 2017.

BRASIL. Ministério da Saúde. Protocolo de atenção à saúde e resposta à ocorrência de microcefalia relacionada à infecção pelo vírus zika, 2016a. Disponível em: < http://www.saude.go.gov.br/public/media/ZgUINSpZiwmbr3/64622069021204406934 .pdf > Acesso em 22 abr. 2017

BRASIL, Patrícia et al. Zika virus infection in pregnant women in Rio de Janeiro. The New England Journal of Medicine, Boston, v. 375, n. 24, p. 2321-2334, dez. 2016b. 
BROUTET, Nathalie et al. Zika virus as a cause of neurologic disorders. The New England Journal of Medicine, Boston, v. 374, n. 16, p. 1506-1509, abr. 2016.

CORDEIRO, Marli Tenorio et al. Positive IgM for Zika virus in the cerebrospinal fluid of 30 neonates with microcephaly in Brazil. The Lancet, New York, v. 387, n. 10030, p. 1811-1812, abr. 2016.

CUGOLA, Fernanda R. et al. The Brazilian Zika virus strain causes birth defects in experimental models. Nature, New York, v. 534, n. 7606, p. 267-271, jun. 2016.

DRUMMOND M; MCGUIRE A. Economic evaluation in health care. New York: Oxford University Press Inc., 2006.

HEUKELBACH, Jorge et al. Zika virus outbreak in Brazil. The Journal of Infection in Developing Countries, Tramariglio, v. 10, n. 02, p. 116-120, fev. 2016.

HABY, Michelle M. et al. Prevalence of Asymptomatic Zika Virus Infection: A Systematic Review. Bulletin of the World Health Organization v.96 n.6 p : 402-413, 2018.

IBGE. Instituto Brasileiro de Geografia e Estatística. Censo Demográfico 2010: Tabela 3175 - População residente, por cor ou raça, segundo a situação do domicílio, o sexo e a idade. Acesso em: 12 de abril de 2018. Disponível em: https://sidra.ibge.gov.br/tabela/3175\#resultado.

KRAUER, F. et al. "Zika Virus Infection as a Cause of Congenital Brain Abnormalities and Guillain-Barré Syndrome: Systematic Review." Ed. Lorenz von Seidlein. PLoS Medicine 14.1 (2017): e1002203. PMC. Web. 21 Sept. 2018.

LOURENÇO, José et al. Epidemiological and Ecological Determinants of Zika Virus Transmission in an Urban Setting. Ed. Mark Jit. eLife, n=6 : e29820. PMC. 2017

LOWE, Rachel et al. The Zika Virus Epidemic in Brazil: From Discovery to Future Implications. International Journal of Environmental Research and Public Health v.15. n. 1 p. $96,2018$.

MLAKAR, J.M.D et. al. Zika Virus Associated with Microcephaly. The New England journal of medicine. V.10, n.374, p:951-8.2016 
MARINHO, Fatima et al. Microcefalia no Brasil: prevalência e caracterização dos casos a partir do Sistema de Informações sobre Nascidos Vivos (Sinasc), 2000 2015. Epidemiologia e Serviços de Saúde, Brasília, v. 25, n. 4, p. 701-712, out-dez. 2016.

MEANEY-DELMAN, Dana et al. Zika virus and pregnancy: what obstetric health care providers need to know. Obstetrics e Gynecology, Washington, v. 127, n. 4, p. 642648, abr. 2016.

MOULIN, E. et al. Simultaneous outbreaks of dengue, chikungunya and Zika virus infections: diagnosis challenge in a returning traveller with associated with microcephaly. The New England Journal of Medicine, Boston, v. 2016, n. 374, p. 951 958, 2016.

Musso D., Gubler D.J. Zika Virus. Clinical Microbiology Reviews. V;29, n=3, p.487524., 2016

NUNES, Magda Lahorgue et al. Microcephaly and Zika virus: a clinical and epidemiological analysis of the current outbreak in Brazil. Jornal de Pediatria.v. 92, Issue 3, p. 230-240. 2016

ORGANIZAÇÃO MUNDIAL DA SAÚDE. Prevenção da transmissão do vírus Zika por via sexual, 2016.2 Disponível em: < http://apps.who.int/iris/bitstream/10665/204421/5/WHO_ZIKV_MOC_16.1_por.pdf >. Acesso em: 21 abr. 2017.

PROGRAMA DAS NAÇÕES UNIDAS PARA O DESENVOLVIMENTO (PNUD). Uma avaliação do impacto socioeconômico do vírus Zika na américa latina e caribe: Brasil, Colômbia e Suriname como estudos de caso. v.1.2017

PETERSEN, Lyle R. et al. Zika virus. The New England Journal of Medicine, Boston, v. 374, n. 16, p. 1552-1563, 2016.

PINTO JUNIOR, Vitor Laerte et al. Zika virus: a review to clinicians. Acta medica portuguesa, Lisboa, v. 28, n. 6, p. 760-765, 2015.

RASMUSSEN, Sonja A. et al. Zika virus and birth defects-reviewing the evidence for causality. The New England Journal of Medicine, Boston, v. 374, n. 20, p. 1981-1987, 2016. 
REIS, Raquel Pitchon dos. O surto de microcefalia no Brasil. Revista Médica de Minas Gerais, Belo Horizonte, v. 25, n. 4, p. 809-810, 2015.

RICE, Dorothy P. Cost of illness studies: what is good about them?. Injury Prevention, London, v. 6, n. 3, p. 177-179, 2000.

SAMPATHKUMAR, Priya; SANCHEZ, Joyce L. Zika Virus in the Americas: A Review for Clinicians. Mayo Clinic proceedings, New York, v. 91, n. 4, p. 514-521, 2016.

VARGAS, Alexander; ESTIMA, Nathalie Mendes. Características dos primeiros casos de microcefalia possivelmente relacionados ao vírus Zika notificados na Região Metropolitana de Recife, Pernambuco. Epidemiologia Serviço Saúde. v. 25 n.4 .2016. WORLD HEALTH ORGANIZATION. Microcephaly. 2016. Disponível em: < http://www.who.int/mediacentre/factsheets/microcephaly/en/ >. Acesso em: 12 abr. 2017.

ZANLUCA, Camila; SANTOS, Claudia Nunes Duarte dos. Zika virus-an overview. Microbes and Infection, v. 18, n. 5, p. 295-301, 2016. 